\title{
Toward a Better Understanding of the Definition of Transdisciplinary Scientific Collaboration
}

\author{
Juliana Fuqua
}

\section{California State Polytechnic University, Pomona}

The question of what is transdisciplinarity and when might a team be considered transdisciplinary is a question posed by health research investigators and practitioners in the U.S. who, over the last 15 years, have seen or responded to calls for transdisciplinary research proposals. The present paper tackles the question by providing the following: contemporary and historical context (including frustrations of social scientists), a definition in which transdisciplinary scientific collaboration is defined as an ideal form of collaboration with a high level of interaction between researchers. A discussion of related terms is also provided.

\section{Context}

Scholars have observed that many of today's health and social problems need to be addressed by more than one scientific discipline (Yang, 2011) and by more than one person. New scientific outcomes and solutions to problems may be achieved with transdisciplinary teams-beyond that achievable by uni-disciplinary teams. In the past, new theories, hypotheses, methods, and other scientific outcomes and new fields have emerged when transdisciplinary teams of scientists worked together. For example, when a psychologist decided to work with an immunologist, the field of psychoneuroimmunology emerged and helped to explain why when a person experiences psychological stress, the immune system can be weakened and the person can become ill. Other trans-disciplinary scientific fields have sprung up as a result of individuals working together across disciplinary lines, creating fields such as cognitive sciences, astrobiology, biogeochemisty, neuropsychopharmacology, biophysics, and behavioral medicine. After teams of scientists merged ideas across disciplines, transdisciplinary scientific research outcomes have also been reported such as the creation of the atomic bomb, the mapping of the genome, and the development of medicine for cancer.

Despite innovations in cancer treatment, cancer is still prevalent and smoking is still a problem. In the U.S., the leading causes of mortality and morbidity among adults (i.e., cancer and heart disease) and among adolescents can be addressed by multiple disciplinary perspectives. To understand why a teen begins to smoke, becomes dependent on nicotine, and later dies prematurely from tobacco-related diseases, scientists have used multiple levels of analysis from a "micro" neuropharmacological approach (studying the effect of cigarette smoke on rat's brains) to a broader or "macro" social psychological approach (studying the effects of anti-tobacco messages in films and other media). These are examples of approaches that are rarely combined across disciplines. The merging of such very different approaches could lead to innovations that might eventually reduce the prevalence and problems associated with tobacco use.

For over 20 years, greater interest in merging ideas across disciplines has been sparked, and a growing number of national and international initiatives have been developed to bring together medical, health, and social scientists to address complex health issues, including several with "transdisciplinary" in the name such as the Transdisciplinary Tobacco Use Research Center initiative and the Transdisciplinary Research on Energetics and Cancer initiative in (National Cancer Institute, 2012a, 2012b). For example, two institutes of the National Institutes of Health (the National Cancer Institute and the National Institute of Drug Abuse) and the Robert Wood Johnson Foundation joined together in 1998 to award \$84 million to establish seven 
Transdisciplinary Tobacco Use Research Centers (TTURCs) at academic research institutions in the U.S. with the goal of developing transdisciplinary models of tobacco use (Turrkan, Kaufman, \& Rimer, 2000). Scientists affiliated with the centers were charged with the task of merging ideas across disciplinary lines, including attempting to merge a "micro" neuropharmacological approach and a more "macro" social psychological approach. ${ }^{i}$ Merging ideas and bridging the gaps between such different approaches have proven challenging, especially for scientists striving to merge ideas across disciplines that are quite diverse and represent a wide span of disciplines. (See Fuqua, 2002, for information about one center that had more success than another in achieving TTURC scientific goals).

\section{Frustrations Lead to a Unique Definition}

When an interdisciplinary team of scientists convene, such as a medical and social science team, team members can find it daunting to merge ideas. There are many barriers to conducting interdisciplinary research that have been experienced and identified in non-empirical reports (Hildebrand-Zanki, Cohen, Perkins, Prager, Stokols, \& Turkkan, 1998; Klein, 1990, 1996; also see work by authors in Chubin, Porter, Rossini, \& Connolly, 1986; National Academies Committee on Science, Engineering, and Public Policy Committee on Facilitating Inter-disciplinary Research, 2005, and the special issue of the American Journal of Preventive Medicine in 2008).

One barrier often experienced by scientists is that one disciplinary perspective tends to dominate, and therefore, ideas are not merged across disciplinary lines. For example, medical doctors often form teams and invite a few social scientists, health promotion specialists, or other non-medical doctors to join a team or larger organization to address a social and health problem. The medical doctors may not recognize the potential value of the team members. The social scientists are often relied upon for a few tasks (e.g., writing a survey), but not drawn upon to help the doctors understand the deeper social, economic, cultural, and psychological factors, which may impede the medical doctors' goal of health care delivery. The team members then do not truly merge ideas across disciplines to develop innovations in practice or in science. Instead, the medical staff delivers medicine.

Such problems were noted as early as the 1940s, when a medical anthropologist wrote about his frustration while working with the World Health Organization, commenting that "the far-sighted medical doctors and international health workers [did not] realize [at first] that effective delivery of health care, especially in cross-cultural settings, involved sociocultural as well as purely medical factors" (as cited in Kessel \& Rosenfield, 2008). He noted that the medical staff would not ask the other team members to identify the social and behavioral factors that might inform a deeper understanding of communities' health conditions, but instead would assign the social scientists the task of writing a questionnaire (without helping the medical doctors understand the sociocultural factors that were impeding the goals of health care delivery). Such problems have continued to plague the World Health Organization and other national and international organizations.

A similar frustration of another social scientist, Patricia Rosenfield, has been published more recently (Kessel \& Rosenfield, 2008). She describes her experience with a World Health Organization team working on the problem of malaria with medical staff and behavioral social scientists. The behavioral scientists ended up frustrated by the lack of merging of ideas across disciplines. Trained as an economist, she was frustrated that teams working on malaria were focused too heavily on a medical perspective, wasting resources and not achieving their potential in addressing the problem of malaria. Her experience was later followed by her creation of a unique definition of transdisciplinarity, and her definition began to be used by a small, but growing number of scholars and funding agents (including those at the National Cancer Institute) who recognized the potential of transdisciplinary scientific teams in the U.S. The term transdisciplinary existed prior to the 1990s but was rarely used, and many different definitions were implied, including one definition in which transdisciplinary meant 
"beyond disciplines" rather than "merging disciplines." Scholars still do not agree upon one clear definition. Rosenfield's definition emerged when social scientists in Europe in the 1990s were engaged increasingly in discussions of crossing disciplinary lines and medical doctors were increasingly inviting social scientists onto their teams.

\section{Defining Ideal Cross-disciplinarity: Transdisciplinary Scientific Teams}

Rosenfield (1992) distinguished between three forms of cross-disciplinary research: multidisciplinary, interdisciplinary, and transdisciplinary. Multidisciplinary occurs when individuals work independently, in parallel, or sequentially from a disciplinespecific basis to address common problems. A team in which members make progress in their own disciplines, but do not merge ideas across disciplines would be considered multidisciplinary. Interdisciplinarity implies a higher level of interaction, cooperation and creativity across disciplines, and can be defined as research in which individuals work jointly, but from a discipline-specific basis to address common problems. Transdisciplinarity denotes the highest level of interaction and can be defined as a process in which individuals work jointly using a shared conceptual framework that draws together discipline-specific theories, concepts, and approaches to address a common problem. The collaboration that led to psychoneuroimmunology would be considered transdisciplinary. (See Rosenfield, 1992, for examples.) Her definition is in line with previous and more common definitions of interdisciplinary work such as Thomson Klein (1996) who notes that interdisciplinary research is defined by efforts to cross the "boundaries" of two different fields or disciplines and to integrate the perspectives, ideas, or methods of two or more fields. In contrast, Rosenfield's conceptualization uniquely denotes how interdisciplinary teams can range from weak to strong levels of interaction.

Transdisciplinary collaborative research has also been further defined, by Stokols and colleagues, as collaboration among scholars representing two or more disciplines, with the products of that collaboration reflecting an integration of conceptual and/or methodological perspectives drawn from two or more fields. It is the extent of integration of transdisciplinary research products--such as hypotheses, theories, and other scientific outcomes--that sets them apart from the more traditional intellectual products of unidisciplinary research. According to Stokols et al. (2003) and Fuqua (2002), scientific teams can achieve transdisciplinarity in subgroups, even if the entire team has not achieved widespread transdisciplinarity.

Some scholars argue that there is no need for the term transdisciplinary, because the terms crossdisciplinary, multidisciplinary, and interdisciplinary can be used interchangeably. However, these terms do not provide a taxonomy or classification for the degree to which an interdisciplinary team has reached its potential-from least to most able to reach ideal collaboration.

Transdisciplinarity is considered a goal to strive for, but it is difficult to achieve due to the extensive time needed to overcome barriers, to gain a deep understanding of two or more disciplines, and to merge ideas in those disciplines. A team is usually necessary to achieve transdisciplinary outcomes, but a single individual could conceivably achieve this.

Transdisciplinarity is not limited to science, but can be achieved by people other than scientists such artists, scholars, and community leaders who integrate ideas across disciplines. One recent definition of transdisciplinary research and practice that incorporates scholars and practitioners is: "an integrative process whereby scholars and practitioners from both academic disciplines and non-academic fields work jointly to develop and use novel conceptual and methodological approaches that synthesize and extend discipline-specific perspectives, theories, methods, and translational strategies to yield innovative solutions to particular scientific and societal problems.”

Distinguishing Transdisciplinary Scienti-fic Collaboration from CBPR and TDAR

Transdisciplinary scientific collaboration is 
sometimes mistaken to be synonymous with terms such as community based participatory research (or CBPR). CBPR occurs when university researchers work in an equal partnership with members of a community (Minkler \& Wallerstein, 2011). In CBPR projects, the community participates fully in all aspects of the research process with the researchers. CBPR is different from transdisciplinary scientific collaboration because, by definition, CBPR involves research conducted with community leaders, and it does not have the goal of achieving scientific innovation, such as new theories. If university researchers from only one discipline work closely with community members, they are not con-ducting interdisciplinary research because usually the community members do not represent a second discipline.

As a published example of CPBR, university researchers joined with community leaders in an organization entitled WINCART: Weaving an Islander Network for Cancer Awareness, Research and Training (Tanjasiri \& Peters, 2010). One research goal was to understand why the cancer mortality rate is decreasing in some ethnic groups, and yet increasing among the nearly 900,000 Pacific Islanders in the U.S. The researchers involved community leaders in all phases of the research process. By working together, new factors were identified that may explain why Pacific Islanders (including Tongans, Samoans and Native Hawaiians, and Chamorros) suffer from higher prevalence of the leading health disparity indicators. ${ }^{\text {ii }}$

While the team might be considered successful in identifying important factors related to cancer, it is unclear whether the team produced transdisciplinary scientific innovations. In line with Rosenfield's definition, the research team would be considered transdisciplinary if the university scientists developed new scientific innovations that created outcomes (e.g., concepts, methods, or findings) that merged two or more disciplines. If the university scholars worked independently in parallel with each other on the common problem, then the team would be categorized as multidisciplinary.
Some transdisciplinary teams conduct transdisciplinary action research, in which the translation of research findings into practical solutions to social problems is emphasized. Transdisciplinary action research (TDAR) comprises at least three kinds or phases of collaboration: (a) scientific collaboration among research investigators (usually housed in universities), (b) community problem-solving coalitions in which researchers work with community members to translate scientific knowledge into community problem-solving strategies, and (c) intersectoral partnerships involving representatives of organizations situated at local, state, national, and international levels, who work together to improve environmental, social, and health problems (Stokols, 2006). As an example, a TTURC began as a scientific collaboration among research investigators (Fuqua, Stokols, Gress, Harvey, \& Phillips, 2004). Some of the research investigators strove to translate the research, and they established the two-year Tobacco Policy Consortium of UC Irvine. The university researchers invited community leaders to hear about their research findings and asked them to help apply the findings to the problem of tobacco use by adolescents. The team generated ideas about how to best conduct interventions tailored to adolescents. Finally, the consortium completed educational information and policy briefs that were distributed to local, state, and national politicians, educators, and staff at other organizations (Fuqua, Stokols, Harvey, Baghery, \& Jamner, 2010).

The preceding discussion provides a brief sketch of information related to defining transdisciplinary scientific collaboration and distinguishing it from other terms. More information is needed to further the discussion of the definition and to elucidate the potential of transdisciplinary scientific collaboration. The definition is the proverbial "tip of the iceberg," and many deeper questions may be posed. For example, what contemporary examples exist of transdisciplinary scientific teams? Why would they be labeled as truly transdisciplinary examples? In what situations are transdisciplinary scientific teams ideal, and when are other forms of research more 
appropriate? How many people and disciplines should be represented on a team? To what extent can individuals, departments, organizations, and society benefit from individuals thinking beyond one disciplinary perspective as they read articles, plan to attend conferences, plan to studies, write reports, aim for tenure or promotion, and train mentees?

In terms of developing, running, or studying a team, practitioners (such as team leaders, team participants, evaluation leaders, mentors, and others) who consider the definition can begin to envision what a successful transdisciplinary scientific team might look like before, during, and after the collaboration occurs. They can begin to envision and establish formal and informal interventions to facilitate their team toward transdisciplinary outcomes. They can study and then modify the situational circumstances that facilitate or impede team efforts. Scholars can add to a growing collection of information as scientists publish retrospective accounts of the process and outcomes of their teams. Scientists may conduct empirical studies of the process and outcomes of their teams and add to the scant but growing number of studies that are being conducted as a nascent field of the "science of team science" develops.

\section{References}

Chubin, D.E., Porter, A.L, Rossini, F.A., \& Connolly, T. (1986). Interdisciplinary analysis and research: Theory and practice of problem-focused research and development. Mt Airy: Lomond Publications.

Fuqua, J., Stokols, D., Harvey, R., Baghery, A., \& Jamner, L. (2010). Transdisciplinary action research on teen smoking prevention: Case study of the UC Irvine Tobacco Policy Consortium. In N. Freudenberg, S. Saegert, \& S. Klitzman (Eds.) Interdisciplinary urban health research and practice (pp.185-216). San Francisco, CA: Jossey-Bass.

Fuqua, J. Transdisciplinary scientific collaboration: An exploration of the research process. Doctoral dissertation (2002). School of Social Ecology, University of California, Irvine.

Fuqua, J., Stokols, D., Gress, J., Harvey, R., \& Phillips, K. (2004). Transdisciplinary scientific collaboration as a basis for enhancing drug abuse prevention research. Substance Use and Misuse, 39 (10-12), 2073-2074.

Fuqua, J., Stokols, D., Harvey, R., Baghery, A., \& Jamner, L. (2010). Transdisciplinary action research on teen smoking prevention: Case study of the UC Irvine Tobacco Policy Consortium. In N. Freudenberg, S. Saegert, \& S. Klitzman (Eds.) Interdisciplinary urban health research and practice (pp.185-216). San Francisco, CA: Jossey-Bass.

Hall, K.L., Stokols, D., Stipelman, B.A., Vogel, A.L., Feng, A., Masimore, B., et al. (2012). Assessing the value of team science: A study comparing center- and investigator-initiated grants. American Journal of Preventive Medicine, 42(2), 157-163.

Hildebrand-Zanki, S., Cohen, L., Perkins, K., Prager, D. J., Stokols, D., \& Turkkan, J. (1998). Barriers to transdisciplinary research in youth tobacco use prevention. A Report from the Working Group To the Youth Tobacco Use Prevention Initiative. Washington, DC: Center for the Advancement of Health and the Robert Wood Johnson Foundation.

Kessel, F., \& Rosenfield, P.L. (2008). Toward transdisciplinary research: historical and contemporary perspectives. American Journal of Preventive Medicine, 35(2), S225-234.

Klein, J. T. (1990). Interdisciplinarity: History, theory and practice. Detroit: Wayne State University Press.

Klein, J.T. (1996). Crossing boundaries: Knowledge, disciplines, and interdisciplinarities. Charlottesville, VA: University of Virginia Press.

Minkler, M., \& Wallerstein, N. (Eds.) (2011). Community-based participatory research for health: From process to outcomes ( $3^{\text {rd }}$ ed.). San Francisco: Jossey-Bass.

National Academies Committee on Science, Engineering, and Public Policy Committee on Facilitating Inter-disciplinary Research (2005). Facilitating Interdisciplinary Research. Washington, DC: National Academies Press. 
National Cancer Institute (a). Transdisciplinary Tobacco Use Research Centers. Available at http://dccps.nci.nih.gov/tcrb/tturc/. Retrieved July 1, 2012.

National Cancer Institute (b). Transdisciplinary Research on Energetics and Cancer Centers. Available at https://www. compass. fhcrc.org/trec/. Retrieved September 1, 2012.

Rosenfield, P. L. (1992). The potential of transdisciplinary research for sustaining and extending linkages between the health and social sciences. Social Science and Medicine, 35, 1343-1357.

Stokols, D. (2006). Toward a science of transdisciplinary action research. American Journal of Community Psychology, 38 (1-2), 63-77.

Stokols, D., Hall, K.L., \& Vogel, A.L. (In preparation). Transdisciplinary Public Health: Definitions, core characteristics, and strategies for success, In D. Haire-Joshu \& T.D. McBride (Eds.) Transdisciplinary public health: Research, methods, and practice. San Francisco, CA: JosseyBass.

Stokols, D., Fuqua, J., Gress, J., Harvey, R., Phillips, K., Baezconde-Garbanati, L., et al. Evaluating transdisciplinary science (2003). Nicotine and Tobacco Research, 5 (1), S21-S39.

Tanjasiri, S.P. \& Peters, R. (2010). Reducing cancer health disparities among Pacific Islanders in the U.S. [Special Issue: Cancer Control]. Californian Journal of Health Promotion, 8, vii-x.

Yang, J.S. (2011). Moving beyond traditional boundaries of health: Public health and multi-sectoral integration. Californian Journal of Health Promotion, 9 (1), v-vi.

(C) 2012 Californian Journal of Health Promotion. All rights reserved.

Author Information

Juliana Fuqua

California State Polytechnic University, Pomona

\footnotetext{
i A recent empirical study investigating the success of such initiatives indicated that, in comparison with R01 grants, the TTURC initiative was successful in garnering higher publication rates and average number of coauthors per publication, relative to investigator-initiated (or R01) grants (Hall, Stokols, Stipelman, Vogel, Feng, et al., 2012).

ii The leading indicators are cigarette smoking, hypertension, obesity, diabetes, infant mortality, tuberculosis, hepatitis B, and asthma (CDC, 2002) which are cross-disciplinary problems. The collaborators identified the following factors which spanned multiple disciplines: lack of communication with medical providers, severe stigma and shame Pacific Islander populations in the future, and genetic risk factors for cancer related to nicotine metabolism (Tanjasiri \& Peters, 2010).of cancer diagnoses, social support needs of survivors from family and church, and the potentially positive role of spirituality in promoting long-term quality of life. The team members noted additional factors, such as culturally appropriate community interventions, slow delivery of cancer advances to
} 